Rev. Saúde públ., S. Paulo, 25 (6): 418-25, 1991.

\title{
Conceito de doença e preservação da saúde de população de professores e escolares de Primeiro Grau*
}

\author{
The concept of disease and of the preservation of health in a sample population of \\ teachers and pupils of a school course for 7-14 year olds
}

\author{
Evely Boruchovitch**, Isabela Cabral Felix-Sousa**, Virgínia T. Schall***
}

\begin{abstract}
BORUCHOVITCH, E. et al. Conceito de doença e preservação da saúde de população de professores e escolares de Primeiro Grau. Rev. Saúde públ., S. Paulo, 25: 418-25, 1991. Considerando-se que a informação acerca de como professores e alunos conceituam doença e o que fazem para cuidar de sua saúde tem importantes implicações para a educação em saúde, estes conceitos foram estudados numa amostra de docentes e escolares de primeiro grau, representativa da zona norte do Município do Rio de Janeiro, RJ (Brasil). Os resultados encontrados são discutidos à luz de duas perspectivas: (a) as contribuições provenientes de teorias cognitivas que abordam formação de conceitos; (b) a influência do contexto social na aquisição, no desenvolvimento e caracterização dos conceitos estudados. Tevese por finalidade contribuir para a educação em saúde no sentido de uma revisão e reflexão crítica da concepção do processo saúde-doença no âmbito escolar atentando-se para os aspectos complexos e multifacetários que este processo envolve.
\end{abstract}

Descritores: Educação em saúde. Formação de conceito. Atitude frente à saúde. Saúde escolar.

\section{Introdução}

A importância do estudo de conceitos e dos processos pelos quais estes se formam reside no fato de, segundo Ausubel e col. ${ }^{3}$ (1980), vivermos, sobretudo, num mundo de conceitos. A investigação na área de formação de conceitos tem se concentrado na análise dos fenômenos cognitivos e sociais envolvidos na aquisição dos mesmos.

$\mathrm{Na}$ linha de investigação cognitiva, ênfase é dada a influência dos processos cognitivos e dos fatores cronológicos no desenvolvido dos conceitos. Destacam-se, nesta perspectiva, Strauss ${ }^{17}$ (1952) e Polanyi $^{12,13}$ (1959, 1967); Piaget ${ }^{11}$ (1987), Ausubel e col. ${ }^{3}$ (1980), Vygotsky ${ }^{19}$ (1987).

Apesar de algumas divergências entre os representantes da perspectiva cognitiva, na formação de conceitos, são compartilhadas premissas básicas

* Pesquisa subvencionada pelo Conselho Nacional de Desenvolvimento Científico e Tecnológico (CNPq90.0074/81) e Coordenação do Aperfeiçoamento de Pessoal de Nível Superior (CAPES/PADCT/SPEC - PI 246/85 e 236/86). Apresentado, parcialmente, na $40^{2}$ Reunião Anual da Sociedade Brasileira para o Progresso da Ciência - SBPC, São Paulo, 1988.

** Doutorandas do Departamento de Psicologia e Sociologia Educacional .. University of Southern California - Los Angeles - USA

*** Departamento de Biologia do Instituto Oswaldo Cruz - Rio de Janeiro, RJ - Brasil.

Separatas/Reprints: V. T. Schall - Av. Brasil, 4365 Manguinhos - 21040 - Rio de Janeiro, RJ - Brasil. comuns como: a) os conceitos são vistos como "alicerces" da experiência cognitiva, cujos significados posteriores não são construídos, mas absorvem os primeiros e mais simples significados; $b$ ) os conceitos emergem como extensão do conhecimento já existente; c) a finalidade básica do conceito é a de facilitar a aquisição de novos conceitos; d) a apredizagem de conceitos é considerada gradativa, contínua e progressiva; e) há ganhos progressivos no nível de abstração no qual ocorre o processo de aquisição de conceitos.

Ausubel e col. ${ }^{3}$ acrescentam que a apredizagem de conceitos não é dependente apenas das propriedades da estrutura cognitiva existente, mas também do estado geral do desenvolvitnento e da capacidade intelectual do aluno tanto quanto da natureza do conceito propriamente dito e da forma pela qual é apresentado ao aluno.

A influência dos fatores sociais na formação de conceitos se faz presente na visão de Bolton ${ }^{4}$ (1977), Toulmin ${ }^{18}$ (1972), Lecourt ${ }^{7}$ (1973) e Novaes ${ }^{9}$ (1970). Importância aqui é atribuída ao fato do sujeito ser membro de uma sociedade num certo momento histórico, sendo guiado por certos valores que se traduzem e se expressam na gênese dos conceitos. Fatores sócio-históricos são vistos como propriciadores das condições para o aparecimento de um determinado conceito, de sua vitalidade, fecundidade e do seu compromisso ou não com idéias dominantes.

Intengrando-se às contribuições das perspectivas cognitiva e social, na formação de conceitos, 
torna-se evidente que o ensino e aprendizagem de conceitos ultrapassam, então, a influência da disponibilidade intelectual e emocional do aprendiz, requerendo percursos outros onde cada conceito, antes de ser ensinado ou transmitido, deve ser pensado como um produto de uma rede de configurações que, ao mesmo tempo, lhe tecem, the imprimem marcas e lhe conferem significados.

Assim sendo, o ensino do conceito de doença remete a uma reflexão sobre as várias dimensões que envolve, bem como de sua natureza complexa e multifacetária.

Para Novaes ${ }^{9}$ (1976), saúde e doença são muito mais valores sociais, historicamente colocados, do que a simples expressão da situação biológica do organismo (em geral), em um meio dado e, portanto, devem ser pensados em termos de sua historicidade.

Considerando que a doença ocorre num dado ambiente, Rouquayrol ${ }^{15}$ (1983) enfatiza que o estado final provocador de uma doença é resultado da sinergização de uma multiplicidade de fatores políticos, econômicos, sociais, culturais, psicológicos, genéticos, biológicos, físicos e químicos.

Dentro da perspectiva da aquisição de conceitos, se por um lado o conceito de doença é um conceito espontâneo, concreto, facilmente adquirido pela criança, visto que se refere a uma experiência direta que ela vivencia, por outro é um conceito formal, abstrato, científico e com atributos essenciais precisos.

Desta forma, para que se possa trabalhar o conceito de doença com estudantes do primeiro grau, em sua amplitude, sem que se priorize qualquer aspecto, em detrimento de outros, deve-se ter em mente que o significado deste conceito não se esgota na sua definição.

Conceituar doença não é simplesmente saber definí-la. Implica, pois, na possibilidade de se compreender sua história, suas conseqüências e, sobretudo, seus complexos determinantes, muitas vezes reduzidos, pelo contexto educacional, às simples interações agente etiológico-hospedeiro.

Acreditando nas conclusões de Amsdorf ${ }^{2}$ (1961) e Davis, 1958 (citado por Ausubel $^{3}$ e col., 1980) de que a instrução verbal sistemática de conceitos abstratos num nível de escolaridade primária, associada ao uso de provas concreto-empíricas, é pedagogicamente confiável e pode acelerar muito a aquisição de conceitos mais elaborados, e no célebre princípio Ausubeliano de que "o mais importante fator isolado que influencia a aprendizagem é o que o aprendiz já sabe", o presente trabalho dá continuidade às investigações de Schall e col. ${ }^{16}$ (1987), sobre o conceito de saúde numa amostra de professores e escolares do primeiro grau do Município do Rio de Janeiro.
Compreender o que professores e alunos do primeiro grau pensam sobre doença e como cuidam de sua saúde, atentar para a importância dos conceitos intuitivos na aquisição dos conceitos científicos, entender esses dados à luz das diferenças cognitivas e das influências sociais, constituem-se, pois, nos objetivos do presente estudo.

\section{Material e Método}

\section{Amostra e critérios de amostragem}

$O$ presente trabalho foi realizado em 10 escolas (5 públicas e 5 particulares) da Zona Norte do Município do Rio de Janeiro, compreendendo os bairros de Manguinhos, Bonsucesso, Olaria, Higienópolis e Ramos, tendo se utilizado duas escolas (uma pública e uma particular) por bairro, representativas do $5^{\circ}$ Distrito de Educação e Cultura (DEC).

A amostra de 123 professores incluiu docentes responsáveis pelo ensino de saúde no primeiro grau, sendo 97 regentes de turma de primeira a quarta séries e os de Ciências e de Programa de Saúde (20 professores), sendo a maioria do sexo feminino, com idade variando de 19 a 46 anos, estando o maior percentual entre 19 a 36 anos.

Quanto à escolaridade, a maior parte possuía curso superior completo, seguido de superior incompleto e segundo grau completo.

Os alunos de primeira a oitava séries, sendo 40 por escola, foram listados por série e por turma e sorteados por computador, sendo 5 alunos por série (escolas de primeira a oitava séries) e 10 alunos por série (escolas de primeira a quarta séries).

A amostra de escolares foi de 394 alunos de primeira a oitava séries, sendo 198 de escolas públicas, 196 de particulares, totalizando 200 do sexo masculino, 191 do feminino e 3 sem dados de identificação. A idade variou de 6 a 18 anos, sendo a faixa etária de 8 a 15 anos a mais representativa da amostra.

\section{Instrumento de medida}

Foi utilizado um questionário para obtenção de dados da amostra que envolvia diversas áreas temáticas, dentre as quais os conceitos de saúde e doença.

O questionário dos professores constava de 20 questões subjetivas e 37 objetivas, e o dos alunos foi dividido em duas partes: uma para terceira a oitava séries, com questões escritas, e outra, para a primeira e segunda séries, com linguagem apropriada à entrevista oral, abordando assuntos semelhantes. 


\section{Aplicação do questionário para professores}

A aplicação dos questionários para professores foi realizada em dias e horários marcados com a direção da escola de modo a não interferir na rotina das atividades escolares. Os docentes eram reunidos em uma sala disponível, onde os entrevistadores, previamente treinados, estabeleciam um "rapport" inicial oferecendo informações acerca dos objetivos da pesquisa, esclarecendo e orientando dúvidas que porventura surgissem. Ênfase foi dada à expressão individual de modo a evitar que discussões paralelas interferissem nas respostas e, consequientemente, nos resultados.

Por ser extenso, o questionário foi realizado em duas etapas, para evitar problemas de cansaço e também devido à ausência de tão longo tempo disponível, por parte dos docentes. A primeira parte continha questões de opiniões e atitudes para serem respondidas livremente, entre as quais encontravamse questões de conceituação de saúde, doença e cuidados com a saúde.

Para evitar a inibição das respostas, os questionários eram anônimos, identificados por numeração em etiqueta adesiva.

\section{Aplicação do questionário para alunos}

Os alunos de primeira e segunda séries, foram entrevistados oralmente, de modo a obter um maior aproveitamento destes escolares, já que esta faixa etária ainda não possui um domínio da leitura e da escrita.

Neste tipo de entrevista, os entrevistadores foram treinados no sentido de estabelecer um bom relacionamento com os alunos, anotando fidedignamente suas respostas, estimulando, esclarecendo e retraduzindo as perguntas, sempre que os alunos demonstravam não compreender. Todos os comentários extras dos alunos foram também registrados.

Para os alunos de terceira a oitava séries, a aplicação do questionário deu-se de forma coletiva, onde dois entrevistadores reuniam-se com os grupos de alunos sorteados, explicavam os objetivos do trabalho, a importância de se responder individualmente, e esclarecendo dúvidas apenas quando solicitados.

Nos dois tipos de aplicação, esclareceu-se que o questionário não valia nota, de modo a amenizar a inibição e favorecer uma expressão mais livre de respostas, por parte dos alunos.

\section{Método de análise}

Foram analisadas questões relativas à conceituação da doença e ao cuidado com a saúde por parte dos professores de primeira a quarta séries, de Ciências (quinta a oitava) e de alunos de primeira a oitava séries do primeiro grau.
As questões: "Como cuida da saúse?" e "O que é doença para você?" foram analisadas seguindo metodologia utilizada para o conceito de saúde (Schall e col $^{16}$., 1987).

Todas as respostas da amostra foram listadas e organizadas em categorias. Estas, quando necessário, foram divididas em subcategorias, que por sua vez foram definidas operacionalmente, de modo a garantir a precisão da análise. A definição operacional das categorias levou em conta tanto a forma quanto o conteúdo para não se perder a abrangência e riqueza das respostas. Cada sujeito foi analisado quanto ao tipo de resposta fornecida, se de uma categoria (presença de apenas uma idéia) ou se de mais de uma categoria (mais de uma idéia).

Para exemplificar o processo de categorização das respostas às questões: "O que é doença?", e "Como é uma criança doente?", seguem-se alguns exemplos. Assim, respostas relativas a opiniões gerais negativas em relação à doença, como: "Doença é uma coisa ruim" (terceira série - escola 4), foram incluídas na categoria "Atribuição de Afetos." Respostas que evidenciam uma avaliação negativa de ordem orgânica ou emocional do estado da pessoa doente, caracterizadas pela presença de verbos como sentir, ficar ou ter alguma coisa, foram incluídas na categoria "sensação", tal como: "... se sente muito mal, se sente que não está tendo a vida como de outras crianças" (primeira série - escola 1). Da mesma forma foram definidas as demais categorias apresentadas na Tabela 1.

Para a questão: "Como cuida da saúde?", foi utilizado o mesmo processo, podendo-se citar o exemplo da categoria denominada "Ações de Cuidados Sociais". Esta incluiu as respostas que apontavam comportamentos valorizados socialmente como importantes no cuidado com a saúde, tais como: "... cuido do meu irmão com carinho, ajudo minha mãe no supermercado, fazer comida, dar banho no meu irmão" (primeira série - escola 2). ".. não roubar, pedir a mãe dinheiro para comprar doce. Não pegar sem a mãe saber porque é falta de educação" (primeira série - escola 5).

As demais categorias apresentadas na Tabela 3 foram criadas da mesma forma, bem como as dos professores (Tabelas 2 e 3 ).

A análise possibilitou traçar uma idéia quantificada dos aspectos levados em conta pelos professores e alunos entrevistados no momento da descrição do que é doença, bem como do que realizam para manutenção da saúde.

\section{Resultados}

\section{Conceito de doença}

As respostas dos alunos foram divididas em 11 
categorias (Tabela 1), relevantes para a compreensão de como concebem a doença. Em $33,9 \%$ das respostas a doença foi associada pelos alunos a uma sensação; $13,8 \%$ referem-se à doença atribuindo-lhe afetos $(8,1 \%)$ ou nomes $(5,7 \%) ; 10,3 \%$ expressam idéias que supostamente podem causar a doença. Em 8,0\% das respostas a doença é associada aos seus antecendentes e/ou suas conseqüências; $8,3 \%$ denotam idéias de descuidos e $8,4 \%$ referemse a providências tomadas em casos de doenças. Apenas $2,6 \%$ das respostas caracterizam a doença como uma perturbação de funcionamento do organismo, tendo esta idéia surgido a partir da quinta série, atingindo o seu valor máximo na oitava série $(14,6 \%)$. É expressivo, ainda, o percentual de respostas na categoria Não sabe $(12,3 \%)$. Os alunos de primeira, segunda e oitava séries emitiram respos- tas caracterizadas pela presença de mais de uma idéia envolvida, ao passo que as de terceira a sétima séries, de predominantemente uma idéia.

No que concerne à conceituação de doença foram analisadas respostas de 81 professores sendo 68 de primeira a quarta séries e 13 de ciências. Os demais professores da amostra responderam questionários onde a questão relativa à doença ainda não havia sido incluída.

As respostas dos professores foram divididas em 9 categorias (Tabela 2). As idéias de desequilíbrio ou mau funcionamento do organismo $(25,2 \%)$ e de ausência de saúde ou defesas $(18,4 \%)$ totalizaram os maiores percentuais em prof. a quarta séries. Foi expressivo, ainda para este grupo, o percentual de respostas em branco ou que mencionam dificuldade de expressão $(35,9 \%)$.

Tabela 1. Percentagem de respostas segundo conceito de doença e série escolar de alunos de primeira a oitava séries do primeiro grau de escolas públicas e particulares do Município do Rio de Janeiro.

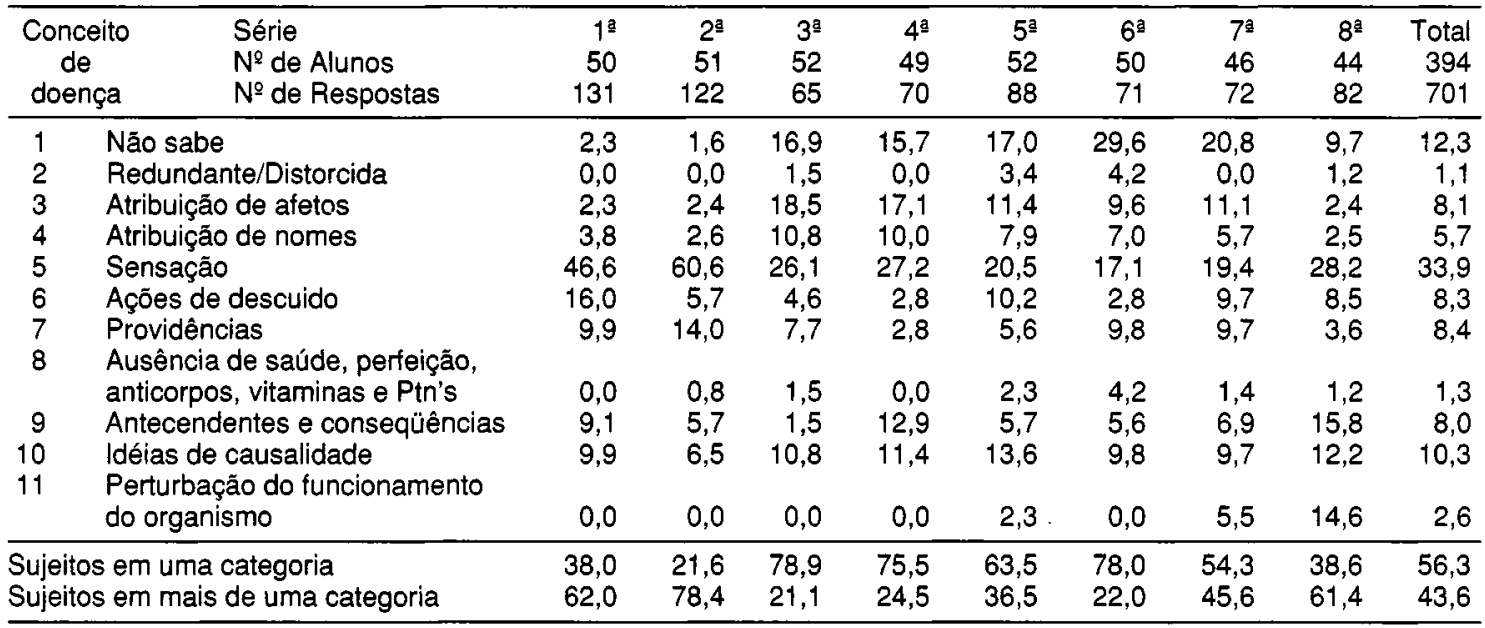

Tabela 2. Percentagem de respostas segundo conceito de doença de professores de primeira a quarta séries e de ciências (quinta a oitava séries) do primeiro grau de escolas públicas e particulares do Município do Rio de Janeiro.

\begin{tabular}{|c|c|c|c|c|}
\hline $\begin{array}{l}\text { Conceito } \\
\text { de } \\
\text { doença }\end{array}$ & $\begin{array}{l}\text { Categorias } \\
\text { № de Professores } \\
\text { № de Respostas }\end{array}$ & $\begin{array}{c}\text { Prot. de } 1^{a} \text { a } 4^{a} \text { séries } \\
68 \\
103 \\
\end{array}$ & $\begin{array}{c}\text { Prof. de Ciências } \\
13 \\
15 \\
\end{array}$ & $\begin{array}{c}\text { Total } \\
81 \\
118 \\
\end{array}$ \\
\hline \multicolumn{2}{|c|}{$\begin{array}{l}\text { 1) Desequilíbrio/Mau funcionamento: } \\
\text { das condições orgânicas e mentais } \\
\text { das condições orgânicas, mentais e sociais } \\
\text { 2) Interferência no estado geral da pessoa } \\
\text { 3) Ausência de saúde ou defesas } \\
\text { 4) Um mal } \\
\text { 5) Mal estar físico ou mental } \\
\text { 6) Processo de causas múltiplas } \\
\text { 7) Inimiga da vida sadia (fome, lixo, agressão } \\
\text { ao meio ambiente, medo, etc.) } \\
\text { 8) Descuido ou mau hábito em relação à saúde } \\
\text { 9) Ausência de resposta/dificuldade } \\
\text { de expressão }\end{array}$} & $\begin{array}{r}25,2 \\
0,0 \\
4,8 \\
18,4 \\
6,8 \\
6,8 \\
1,0 \\
1,0 \\
0,0 \\
35,9 \\
\end{array}$ & $\begin{array}{r}6,7 \\
13,3 \\
33,2 \\
6,7 \\
6,7 \\
6,7 \\
6,7 \\
\\
6,7 \\
6,7\end{array}$ & $\begin{array}{r}22,9 \\
1,7 \\
8,5 \\
16,5 \\
6,8 \\
6,8 \\
1,7 \\
\\
1,7 \\
0,8\end{array}$ \\
\hline $\begin{array}{l}\text { Sujeitos em u } \\
\text { Sujeitos em }\end{array}$ & $\begin{array}{l}\text { goria } \\
\text { ma categoria }\end{array}$ & $\begin{array}{l}86,7 \\
13,2\end{array}$ & $\begin{array}{l}84,6 \\
15,4\end{array}$ & $\begin{array}{l}86,4 \\
13,6\end{array}$ \\
\hline
\end{tabular}


Diferentemente dos professores de primeira a quarta séries, a idéia de inteferência no estado geral da pessoa $(33,2 \%)$ é a que mais representa o pensamento dos professores de ciências acerca do que é doença, apresentando, ainda, um baixo percentual de respostas em branco $(6,7 \%)$ e de idéias ligadas à ausência de saúde ou de defesas $(6,7 \%)$.

Semelhante aos professores de primeira a quarta séries, encontrou-se $20,0 \%$ das respostas de professores de ciências na categoria de desequilíbrio ou mau funcionamento das funções orgânicas, mentais e sociais, sendo que destas, apenas $13,3 \%$ referem-se ao aspecto social envolvido na doença.

No que diz respeito ao tipo de resposta, tanto os professores de primeira a quinta séries, quanto os de ciências emitiram respostas predominantemente de uma idéia.

\section{Idéias de causalidade da doença}

Foram analisadas as idéias que relacionam a doença ao que pode causá-la, tanto da forma correta quanto absurda, as quais revelam aspectos cognitivos e sociais da amostra.

Encontrou-se 72 repostas (10,3\% do total de respostas da amostra) que foram divididas em 8 categorias, sendo as mais expressivas as que indicam o descuido $(50,0 \%)$ e os agentes etiológicos e/ ou transmissores $(33,3 \%)$ como causas de doenças.

A categoria de descuido é expressiva para todas as séries, atingindo o seu valor máximo na primeira série $(80 \%)$, seguido de $60,0 \%$ (quinta série), tendo o valor mínimo de $20,0 \%$ (oitava série) e totalizando $50,0 \%$ das respostas.

$\mathrm{Na}$ categoria referente a agentes etiológicos e transmissores, o percentual de respostas oscila entre $6,6 \%$ (primeira série) a $80,0 \%$ (terceira série), ganhando uma certa expressividade a partir da segunda série $(12,5 \%)$, totalizando $33,3 \%$ das respostas.

Idéias ligadas a contágios $(2,8 \%)$, falta de anticorpos $(2,8 \%)$, de vitaminas $(2,8 \%)$ e outros fatores ambientais $(2,8 \%)$, paralisia $(2,8 \%)$, impossibilidade do organismo reagir aos germes $(2,8 \%)$, perfazem juntas $16,8 \%$ das respostas.

\section{Cuidados com a saúde}

As respostas dos professores a essa questão foram organizadas em 6 grandes categorias e as dos alunos em 5 , de conteúdos bastante aproximados (Tabela 3).

A categoria mais expressiva tanto para professores quanto para alunos foi a de "Ação de Cuidados Físicos", totalizando 92,3\% para professores (primeira a quarta séries), $82,8 \%$ para professores de ciências e $89,7 \%$ para alunos. Esta categoria foi dividida em subcategorias dentre as quais destacamse aquelas que associam o cuidado com a saúde à higiene, alimentação e busca de atendimento médico/farmacológico, entre outros.

As idéias ligadas à prevenção, apesar de oscilantes ao longe das séries, totalizaram $14,6 \%$ para a amostra de alunos, sendo inexpressivas para os 2 grupos de professores, não ultrapassando $6,0 \%$.

Tabela 3. Percentagem de respostas segundo cuidado com a saúde de alunos e professores de primeira e quarta séries e de ciências (quinta a oitava séries) do primeiro grau, de escolas públicas e particulares do Município do Rio de Janeiro.

\begin{tabular}{|c|c|c|c|c|c|}
\hline $\begin{array}{l}\text { Conceito de } \\
\text { cuidado com } \\
\text { a saúde }\end{array}$ & $\begin{array}{l}\text { Categorias } \\
N^{2} \text { de sujeitos } \\
N^{2} \text { de respostas }\end{array}$ & $\begin{array}{c}\text { Alunos } \\
394 \\
660\end{array}$ & $\begin{array}{c}\text { Prof. }\left(1^{a} \text { a } 4^{a}\right) \\
97 \\
208\end{array}$ & $\begin{array}{c}\text { Prof. (Ciências) } \\
20 \\
35\end{array}$ & $\begin{array}{c}\text { Total Prof. } \\
117 \\
243\end{array}$ \\
\hline \multicolumn{2}{|c|}{$\begin{array}{l}\text { 1. Não sabe } \\
\text { 2. Açōes de cuidado físico } \\
\text { 2.1. Geral } \\
\text { 2.2. Alimentação } \\
\text { 2.3. Higiene } \\
\text { 2.3.1. Pessoal } \\
\text { 2.3.2. Preservação da aparência } \\
\text { 2.3.3 Alimentar e habitacional } \\
\text { 2.4. Sono/Repouso } \\
\text { 2.5. Atividade física } \\
\text { 2.6. Prevenção física } \\
\text { 2.7. Tratamento } \\
\text { 3. Lazer e divertimento } \\
\text { 4. Açōes e cuidados sociais } \\
\text { 5. Ausência de cuidados } \\
\text { 6. Outros tipos de cuidados }\end{array}$} & $\begin{array}{r}4,2 \\
89,7 \\
3,2 \\
21,3 \\
27,8 \\
20,1 \\
3,2 \\
4,4 \\
2,4 \\
3,0 \\
14,6 \\
12,3 \\
1,8 \\
3,8 \\
0,6 \\
-\end{array}$ & $\begin{array}{r}1,4 \\
92,3 \\
4,8 \\
20,7 \\
35,6 \\
21,2 \\
11,5 \\
2,9 \\
4,8 \\
3,8 \\
2,4 \\
20,2 \\
2,4 \\
1,0 \\
2,9 \\
0,0\end{array}$ & $\begin{array}{r}2,8 \\
82,8 \\
22,8 \\
14,3 \\
8,6 \\
5,7 \\
2,8 \\
0 \\
2,8 \\
8,6 \\
5,7 \\
20,0 \\
0 \\
0 \\
5,7 \\
8,6\end{array}$ & $\begin{array}{r}1,6 \\
91,0 \\
7,4 \\
19,7 \\
31,7 \\
18,9 \\
10,3 \\
2,5 \\
4,5 \\
4,5 \\
2,9 \\
20,2 \\
2,0 \\
0,8 \\
3,3 \\
1,2\end{array}$ \\
\hline \multicolumn{2}{|c|}{$\begin{array}{l}\text { Sujeitos em uma categoria } \\
\text { Sujeitos em mais de uma categoria }\end{array}$} & $\begin{array}{l}55,2 \\
44,7\end{array}$ & $\begin{array}{l}38,1 \\
61,8\end{array}$ & $\begin{array}{l}65,0 \\
35,0\end{array}$ & $\begin{array}{l}42,7 \\
57,3\end{array}$ \\
\hline
\end{tabular}


As idéias de cuidados ligadas ao lazer e divertimento foram inexpressivas para os 3 grupos estudados: $2,4 \%$ (professores de primeira a quarta séries); $0,0 \%$ (professores de ciências) e 1,8\% (alunos).

Tanto para professores de primeira a quarta séries e ciências, quanto para alunos foram encontrados resultados inexpressivos ligados à idéia de cuidados sociais, sendo respectivamente $1,0 \% ; 0,0 \% \mathrm{e}$ $3,8 \%$ e à idéia de ausência de cuidados $2,9 \% ; 5,7 \%$ e $0,6 \%$.

Quanto ao tipo de respostas, $61,8 \%$ dos professores de primeira a quarta séries emitiram respostas caracterizadas pela presença de mais de uma idéia (em mais de uma categoria) inversamente, 65\% dos professores de Ciências forneceu respostas de apenas uma idéia (uma categoria).

Dentre os alunos, $52,2 \%$ emitiram respostas em uma categoria e $44,7 \%$ em mais de uma categoria. Respostas contendo mais de uma idéia foram mais presentes nas primeiras e segundas séries e nas sétimas e oitavas séries.

Respostas de conteúdos sociais à questão: "Como cuida da Saúde?"

Ainda que quantitativamente pouco representativos, os aspectos sociais (citados por 3,8\% dos alunos) expressam atitudes, valores e relacionamentos que alguns alunos vinculam à saúde, revelando uma abordagem qualitativamente diferente da grande maioria que não associa o cuidado com a saúde a qualquer idéia ou comportamento de cunho social. Desta forma, foi realizada uma análise isolada da presença de tais idéias. Encontrou-se 28 respostas que foram agrupadas em 8 categorias, dentre as quais vale destacar: a) relevância do estudo e as atividades escolares $(25 \%)$; b) o respeito aos pais, parentes e professores $(17,8 \%)$; c) a cooperação com pais e parentes $(17,8 \%)$ e d) a importância do trabalho $(14,3 \%)$.

A categoria relativa à importância da escola e do estudo, tem um percentual inferior a $10 \%$ na primeira série e superior a $33 \%$ nas segundas, quintas, sétimas e oitavas séries. As idéias ligadas a respeito e obediência aus pais, professores e parentes e à importância do trabalho só ocorreram nas primeiras e segundas séries. A categoria referente à ajuda a pais e parentes revelou percentual de $36,4 \%$ para a primeira série e de $50 \%$ para a quarta série. Respostas ligadas à não aderência a vícios representam $10,7 \%$ do total, aparecendo apenas nas sétimas e oitavas séries ( $100 \%$ e $50 \%)$; as relativas a roubo encontramse somente na primeira série $(9,1 \%)$ e as referentes à não agressão aos colegas na segunda série $(11,1 \%)$.

\section{Discussão}

$\mathrm{O}$ estudo permite mostrar que tanto a doença como a preservação de saúde são vistas por professores e alunos, predominantemente pelos seus aspectos biológicos e orgânicos.

Desde a ausência de respostas às respostas mais detalhadas, os professores demonstram não possuírem uma concepção da doença enquanto processo, encontrando-se suas respostas, muitas vezes, limitadas às consequiências da doença, à idéia de ausência de saúde, ou restritas à definição fornecida pela Organização Mundial de Saúde, embora sem a dimensão social.

Os resultados encontrados para amostras de escolares são discutidos tanto em função das supostas diferentes fases cognitivas de acordo com a faixa etária, quanto do tipo de entrevista utilizada, diferente para as primeiras e segundas séries.

A análise por faixa etária parece indicar que em nível dos estágios de desenvolvimento propostos por Piaget, os alunos poderiam ser assim distribuídos: de primeira a segunda séries, encontrando-se possivelmente no período operacional concreto; de terceira e quarta séries, no final do período operacional concreto; quinta a oitava séries, no período de operações formais.

Os alunos, em sua maioria, consideram a doença como uma sensação negativa, principalmente de ordem física e ligada a uma pessoa. A idéia de sensação pressupõe a compreensão de idéia de estado, pois como sugere Ausubel e col. ${ }^{3}$ (1980), a aquisição de palavras como estado, entre outras, representa um avanço no nível de desenvolvimento cognitivo, contribuindo na transição do funcionamento cognitivo concreto para o abstrato.

De modo geral, os alunos de terceira a sétima séries fornecem respostas mais típicas do período pré-operacional e operacional concreto do que alunos de primeira, segunda e oitava séries.

Atribuiram-se os resultados obtidos para primeira e segunda séries à diferença quanto ao tipo de entrevista utilizada, oral (para estas), e ao fato da oitava série, de certa forma, diferenciar-se mais das outras séries, por ser uma série limite e de transição entre o primeiro e segundo graus. Segundo Moysés e Aquino ${ }^{12}$ (1987), na oitava série ocorre a consolidação de dois polos opostos: de um lado o aluno apreendeu que a regra do jogo envolve decorar, responder e receber aprovação, de outro lado sabe que precisa entender, criticar e criar.

A diferença na modalidade de entrevista revelou que alunos de nível cognitivo supostamente operacional concreto demonstraram possuir competências cognitivas de períados mais avançados de desenvolvimento cognitivo.

Segundo Novak ${ }^{10}$ (1981), a capacidade das cri- 
anças de primeira e segunda séries, de adquirir e usar conceitos, é muito maior que muitos educadores têm apregoado, o que possibilita pensar na viabilidade da antecipação do ensino de conceitos mais complexos como saúde-doença e outros, nas primeiras séries escolares.

Além das considerações sobre a formação de conceitos de doença, outras respostas revelam aspectos relativos a atitudes e/ou comportamento dos alunos e professores referentes à questão da preservação da saúde.

$\mathrm{O}$ tipo de cuidado mais relatado por professores e alunos foi o físico. Dentro do que se traduz por cuidados físicos, Rachis ${ }^{14}$ (1985) aponta que os cuidados alimentares e gerais são sempre mais mencionados por escolares norte-americanos na manutenção da saúde.

Apesar da importância concedida à alimentação ter sido expressiva tanto para professores quanto alunos, encontrou-se um percentual ligeiramente maior de respostas de higiene, sobretudo pessoal. Pelo currículo oficial da Secretaria Municipal de Educação (SME) e pela análise do conteúdo dos livros de ciências, o ensino sobre saúde era centrado em hábitos de higiene, pois como aponta Alves ${ }^{1}$ (1987), existe nos livros de saúde uma preocupação muito maior em inculcar regras e hábitos sadios do que contribuir para o despertar de uma consciência reflexiva e crítica do processo saúde-doença. Além disso, a carência alimentar brasileira pode ser um dos fatores que reflete a indicação ligeiramente inferior deste item. Este aspecto reforça a idéia de Bolton ${ }^{4}$ (1977) de que os conceitos são construídos socialmente, num dado momento histórico e guiados por certos valores.

Os professores consideraram também como relevantes para a preservação da saúde, a busca de atendimento médico-farmacológico, o que se refere muito mais à ação curativa do que preventiva. Os alunos, de modo geral, concedem importância maior à prevenção do que os professores, muito embora os percentuais desta categoria decresçam à medida em que a série escolar avança, aproximando-se das respostas dos professores.

Acredita-se que a ênfase maior à higiene, à cura e a regras para a manutenção da saúde, centradas em comportamento de evitação, seja reflexo da mentalidade vigente que se preocupa muito mais com os aspectos manifestos e observáveis do comportamento do que com o desenvolvimento de uma postura que promova a saúde como modo de viver.

Como se pode constatar pelo depoimento dos professores, a concepção saúde-doença precisa ser repensada no contexto escolar. Quanto às contribuições das teorias do desenvolvimento cognitivo, estas podem auxiliar valiosamente à compreensão deste processo.
Por um lado, é necessário que os professores tenham um espaço para refletir sistemática e criticamente sobre suas crenças e práticas em saúde, para que saúde e doença possam ser pensadas não em termos de se constituírem, exclusivamente, como conceitos complexos, abstratos e de difícil apreensão por parte dos alunos, mas sim como conceitos que se constroem a partir da troca de saberes que deve ocorrer no processo ensinoaprendizagem.

Por outro lado, é imprenscindível que os professores tenham um conhecimento maior acerca do desenvolvimento cognitivo humano, sensibilizandose para a importância de conceitos intuitivos dos alunos na construção de conceitos científicos, visto que a maior parte dos métodos e teorias educacionais se baseia, segundo Vygotsky ${ }^{19}$ (1987), na concepção de que os conhecimentos científicos não têm nenhuma história interna, isto é, não passam por nenhum processo de desenvolvimento, sendo absorvidos já prontos mediante processo de comprensão e assimilação.

As contribuições das teorias cognitivas precisam também ser reavaliadas dentro da escola para que possam ser aproveitadas à luz de uma perspectiva que valorize a ampliação da capacidade cognitiva do educando, ao invés de serem utilizadas para estigmatizar, restringir ou rotular o aluno a uma determinada etapa do seu processo de desenvolvimento cognitivo. Deve-se, ainda, atentar para o importante papel da escola no alcance dos níveis mais elevados do desenvolvimento cognitivo, pois, como demonstra Freitag ${ }^{5}$ (1986), "a escolaridade integral das crianças tem condições de desobstruir o processo psicogenético, assegurando sua plena realização."

E à educação em saúde cabe criar condições para a construção de um conceito de saúde e doença que leve em conta as condições de vida e de trabalho geradoras de doenças como aponta Matida e col.* (1985) e que contribua, desta forma, não só para despertar nos alunos o sentimento de que é possível transformar a realidade, mas também para conscientizá-los de que a saúde é um direito, e como tal, deve, segundo Gigase ${ }^{6}$ (1987), ter prioridade na hierarquia dos valores.

BORUCHOVITCH, E. et al. [The concept of disease and of the preservation of health in a sample population of teachers and pupils of a school course for 7-14 year olds]. Rev. Saúde públ., S. Paulo, 25: 418-25, 1991. In

* Projeto de Práticas Simplificadas em Sáude Escolar: Considerações sobre uma experiência vivida com os alunos, pais e professores da Baixada Fluminense Escola Nacional de Saúde Pública FIOCRUZ. (Dados inéditos) 
view of the fact that information about how teachers and students conceptualize illness and their ideas of health preservation have important implications of health education, these two concepts were studied in a sample population of teachers and pupils, of a school course of up to 14-year-olds, representative of the northern area of Rio de Janeiro County. The results obtained are discussed in the light of two approaches: (a) the contributions from the cognitive theorics of concept formation; (b) the influence of the social context in the acquisition, development and characterization of the concepts studied. This study was undertaken with a view to contributing to the field of health education by means of critical review and reflection on the concept of the health illness process in schools, in view of the complex and multidimensional aspects involved in the process.

Keywords: Health education. Concept formation. Attitude to health. School health.

\section{Referências Bibliográficas}

1. ALVES, N.C. A saúde na sala: uma análise nos livros didáticos. São Paulo, Cortez Edit, 1987. p. 38-53. (Cademos Cedes, 18).

2. ARNSDORF, V.E. An investigation of the teaching of chronology in the sixth grade. $J$. exper. Educ. 29: 207-14, 1961.

3. AUSUBEL, D.P.; NOVAK, J.D.; HANESIAN, R. Psicologia educacional. Rio de Janeiro, Edit. Interamericana, 1980.

4. BOLTON, N. The concept formation. New York, Pergamon Press, 1977.

5. FREITAG, B. Sociedade e consciencia: um estudo piagetiano na favela e na escola. São Paulo, Cortez Edit., 1986.

6. GIGASE, P. Como convivem doenças, pacientes e médicos: a noção de saúde. Correio Unesco, 15(10): 4-6, 1987.
7. LECOURT, D. Para uma crítica de la epistemologia. Buenos Aires, Sigle XXI, 1973.

8. MOYSES, L.M.M. \& AQUINO, L.M.C.T. As características do livro didático e os alunos. São Paulo, Cortez Edit., 1987. p. 5-14 (Caderno Cedes, 18).

9. NOVAES, R.L. A saúde e os conceitos. São Paulo, 1976. [Dissertação de Mestrado - Faculdade de Medicina da USP].

10. NOVAK, J.D. Uma teoria de educação. São Paulo, Livr. Pioneira Edit., 1981.

11. PIAGET, J. Seis estudos de psicologia. Rio de Janeiro, Forense Universitária, 1987.

12. POLANYI, M. The study of man. London, Routledge \& Kegan Paul, 1959.

13. POLANYI, M. The tacit dimension. London, Routledge \& Kegan Paul, 1967.

14. RACHIS, S.R. Child's understanding of health. Arch. gen Psych., 12: 10-7, 1965.

15. ROUQUAYROL, M.Z. Epidemiologia e saúde. Fortaleza, Universidade de Fortaleza, 1988.

16. SCHALL, V.T.; JURBERG, P.; BORUCHOVITCH, E.; FELIXSOUSA, I.; ROZEMBERG, B.; VASCONCELLOS, M.C. Health education for children: developing a new strategy; Proceedings of the Second International Seminar on Misconception and Educational Strategies in Science and Mathematics. Ithaca, N.Y., Cornell University, 1987. v. 2, p. 390-403.

17. STRAUSS, A. The development and transformation of monetary meaning in the child. Amer. sociol. Rev., 17: 275-86, 1952.

18. TOULMIN, S. Human understanding: the collective use and evaluation of concepts. Princeton, Princeton University Press, 1972. v. 1.

19. VYGOTSKY, L.S. Pensamento e linguagem. São Paulo, Martins Fontes, 1987.

Recebido para publicação em 22/08/1989. Reapresentado em 02/10/1991. Aprovado para publicação em 21/10/1991. 